\title{
Knowledge, Attitude and Practices of Expectant Mothers on Physical Activity - A Comparative Study
}

\author{
Anam Fatima1, Dr. P. Ashlesha \\ ${ }^{1}$ Master's Student, ${ }^{2}$ Assistant Professor \& Former Head \\ ${ }^{1,2}$ Osmania University College for Women, Hyderabad, Telangana, India
}

\begin{abstract}
How to cite this paper: Anam Fatima | Dr. P. Ashlesha "Knowledge, Attitude and Practices of Expectant Mothers on Physical Activity - A Comparative Study" Published in International Journal of Trend in Scientific Research and Development (ijtsrd), ISSN: 24566470, Volume-3 | Issue-4, June 2019, pp.354-358, URL: https://www.ijtsrd.c om/papers/ijtsrd23 745.pdf

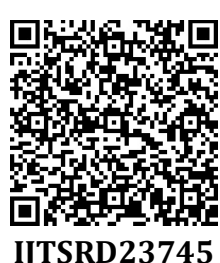

Copyright (C) 2019 by author(s) and International Journal of Trend in Scientific Research and Development Journal. This is an Open Access article distributed under the terms of the Creative Commons

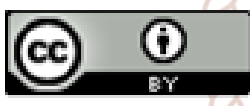
Attribution License (CC BY 4.0) (http://creativecommons.org/licenses/ by/4.0)

\begin{abstract}
Pregnancy is often considered a crucial and complete metamorphic stage in a woman life. Undoubtedly as you continue your pregnancy, you will have numerous questions about various aspects of having a healthy and safe pregnancy. Being physically active during pregnancy contributes significantly towards the health and wellbeing of the mother as well as the child. The aim of the current study is understand the knowledge, attitude and practices of expectant mothers towards physical activity in pregnancy. A total of 100 expectant mothers in the third trimester, 50 of government hospital and 50 of private hospitals, were selected from different maternity hospitals across the city, Hyderabad, through random sampling. The data was collected through selfadministered questionnaires. Data compilation was done using Microsoft excel version 2010 and statistically analysed using chi-square test. The results revealed that while majority of the expectant mothers from both the hospital settings agreed that physical activity is important during pregnancy, they reported decrease in physical activity following pregnancy which may be attributed to various reasons like the lack of advice from health care providers regarding physical activity (majorly among the government hospital women) and reported barriers like fatigue and pregnancy discomfort, lack of time and fear regarding the safety of physical activity during pregnancy. It was observed that greater number of expectant mothers of the government hospital performed adequate physical activity when compared to their counterparts. Thus, the study concludes that although there was no statistically significant difference in knowledge regarding the guidelines for physical activity in pregnancy; yet the expectant mothers of government hospitals were more physically active than that of expectant mothers of the private hospital.
\end{abstract}

Keywords: Physical activity, Expectant mothers, Pregnancy

\section{INTRODUCTION}

Pregnancy is a crucial phase in a woman and her unborn child"s life as it lays the foundation for the health and wellbeing of the mother and the baby for the rest of the life. Hence, maternal health is manifested as a worldwide health priority. Maternal health refers to the health of the women during pregnancy, childbirth and the post-partum period (World Health Organisation, 2010).

An active lifestyle before and during pregnancy is beneficial for maintaining the health and wellbeing of the individual. Physical activity has been defined as „any bodily movements produced by skeletal muscles that require energy expenditure" such as activities undertaken while working, playing, carrying household chores, travelling and engaging in recreational actions like yoga, swimming, dancing (https://www.who.int/dietphysicalactivity/pa/en/).

It is recommended that pregnant women should engage in moderate aerobic exercise for 30 minutes a day, on most days of the week, with an exception of women with compromising health conditions (American College of Obstetricians and Gynaecologists, 2015). An aerobic exercise is that in which one tends to move large muscles of the body (like those of the legs and arms) in a rhythmic way. Moderate intensity means you are moving enough to raise your heart rate and start sweating (https://www.acog.org/Patients/FAQs/Exercise-DuringPregnancy?)

Pregnancy is no longer considered a condition for confinement rather it is recognised as a unique time for behaviour modification among the individuals. Being physically active and participating in exercise throughout pregnancy has been documented to have positive impact on maternal health outcomes like an improvement in cardiovascular and metabolic function, increased strength and bone density (Prather et al.,2012). It is further indicated that regular physical activity appears to lower the risk of gestational diabetes mellitus, gestational hypertension, and preeclampsia (Hegaard et al., 2007).

Physical activity during pregnancy can limit excessive gestational weight gain and prevent postpartum weight retention (Phelan, 2010), and thus helps in preventing 
numerous adverse maternal health outcomes. Physical activity has also been associated with positive birth outcomes like Shortened labour and a lower rate of operative/instrumental delivery (Tinloy et al., 2014; Perales et al., 2016). Studies have shown that regular exercise even in the 3rd trimester neither leads to an increased rate of premature delivery nor to increased hospitalisation (Barakat et al., 2014; Tinloy et al., 2014). Moreover, physical activity during pregnancy is found to impart positive effects on the new-born in terms of long-term risk of chronic metabolic, cardiovascular and oncological diseases (Blaize et al., 2015).

Despite the projected health benefits and guidelines for safe excersing, very few women are found to be physically active in pregnancy (Gaston and Vamos, 2013). Hence, it is crucial to understand whether or not the pregnant mothers have been sufficiently informed about the various dynamics of physical activity during pregnancy. And if they have been advised sufficiently, it is important to understand what are the factors preventing them from exercising during pregnancy.

In view of the above literature, the aim of this comparative study is to examine the presence of any association between the knowledge, perception and practice of physical activity and thereby, study the barriers and promoters to physical activity during pregnancy.

\section{MATERIALS AND METHODS}

A cross-sectional survey was conducted to examine the knowledge, attitude and practice regarding physical activity among the expectant mothers. A random sampling method was employed to select the subjects. The subjects included a total of 100 pregnant women in the third trimester form both government $(n=50)$ and private hospital $(n=50)$, Hyderabad. Pregnant women in the third trimester 18-37 years) were specifically selected because they would better relate to the parameters under study and promptly describe their attitudes and practices on these parameters throughout the pregnancy period. A self-structured questionnaire was employed to collect information like general information, Anthropometric data-such as height and weight (weight at two instances i.e. pre-pregnancy weight and present weight) by using standard measuring scales and also the reports of the patients.

Information on Physical Activity was obtained by collecting data (through self-structured questionnaire) on the physical activity levels before pregnancy, perception about change in activity due to pregnancy, awareness of the ACOG recommended guidelines for physical activity during pregnancy, the practice of physical activity, and also the promoters and barriers to physical activity. The data collected was consolidated using Microsoft excel (2010) and subjected to statistical analysis using chi-square test.

Practice of physical activity: Expectant mothers who performed physical activity as per the ACOG guidelines (those who reported $\geq 30$ minutes of PA per day for more than 3 days a week) were considered to be performing Adequate PA, while those who performed less than these recommended levels were considered to be performing Inadequate PA.

\section{RESULTS AND DISCUSSION}

A total of 50 expectant mothers of government hospitals and 50 expectant mothers of private hospitals were evaluated, aged 18-37 years, of whom $44 \%$ of expectant mothers of government hospitals and $60 \%$ of the expectant mothers of private hospitals were found to be nulliparous, while $56 \%$ of expectant mothers of government hospitals and $40 \%$ of private hospitals were multiparous.

The mean pre-pregnancy weight of expectant mothers from government hospitals was $58.2 \pm 11.2 \mathrm{Kg}$ and that of private hospitals was $61 \pm 10.4 \mathrm{Kg}$, while the mean present weight was about $71 \pm 10.8 \mathrm{Kg}$ in expectant mothers of government hospitals and $74.3 \pm 10.2 \mathrm{Kg}$ in expectant mothers of private hospitals.

Table-1: Socio-demographic details of the expectant mothers

\begin{tabular}{|c|c|c|}
\hline DETAILS & $\begin{array}{l}\text { GOVERNMENT } \\
\text { HOSPITAL }\end{array}$ & $\begin{array}{l}\text { PRIVATE } \\
\text { HOSITALS }\end{array}$ \\
\hline \multicolumn{3}{|c|}{ LEVEL OF EDUCATION } \\
\hline No education & $12 \%$ & $0 \%$ \\
\hline Primary & $16 \%$ & $2 \%$ \\
\hline High school & $34 \%$ & $20 \%$ \\
\hline Intermediate & $26 \%$ & $14 \%$ \\
\hline Graduate or above & $12 \%$ & $64 \%$ \\
\hline \multicolumn{3}{|c|}{ INCOME OF THE FAMILY } \\
\hline$\leq 3$ lakh/yr. & $78 \%$ & $0 \%$ \\
\hline 3-10 lakh/yr. & $20 \%$ & $40 \%$ \\
\hline$\geq 3$ lakh $/$ yr. & $2 \%$ & $60 \%$ \\
\hline \multicolumn{3}{|c|}{ OCCUPATION } \\
\hline nent Working & $22 \%$ & $32 \%$ \\
\hline Non-working & $78 \%$ & $68 \%$ \\
\hline
\end{tabular}

Table-1 depicts that expectant mothers recruited from government hospital had less education qualification; lower annual income and majority of them were non-working. In contrast to this setting, majority of expectant mothers from private hospitals were well-educated, hadmiddle-high income, and a greater percentage of them were working when compared to their counterparts.

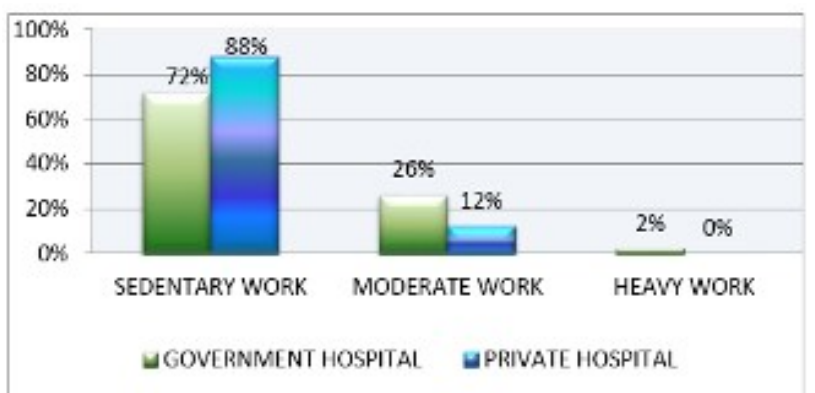

Figure-1: Type of physical activity before pregnancy

Figure-1 shows that the expectant mothers of government hospital were more physically active than their private hospital counterparts before pregnancy. It shows that a majority of women of private hospitals were found to be performing sedentary work even before commencement of pregnancy, with a very small proportion of women performing moderate intensity work. 


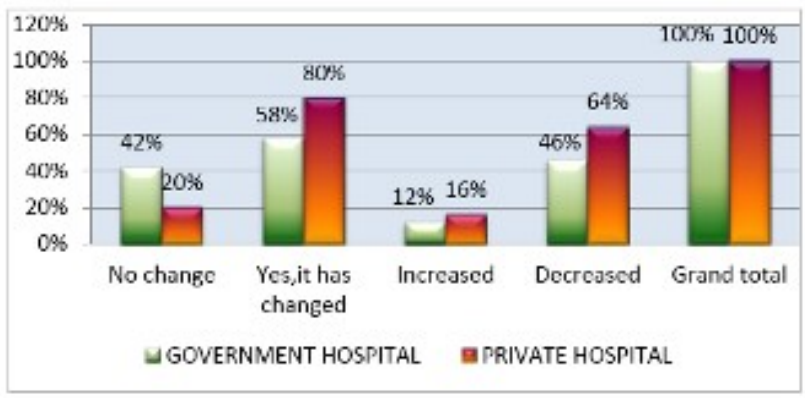

Figure-2: Perception about change in physical activity due to pregnancy

It is observed in figure-2 that the expectant mothers of private hospitals were more likely to report that the physical activity has changed following pregnancy, while a greater number of respondents from government hospitals reported no change in physical activity due to pregnancy. Of those who reported change in physical activity due to pregnancy, majority of them reported that there is a decrease in activity levels in pregnancy. The outcome of this study supports the study conducted by Astrid Merkx et al., (2017) on Factors affectingperceived change in physical activity in pregnancy, which indicated that more than half of the pregnant women reported decrease in physical activity during pregnancy and this perception was more pronounced in women who considered themselves as more active before pregnancy.

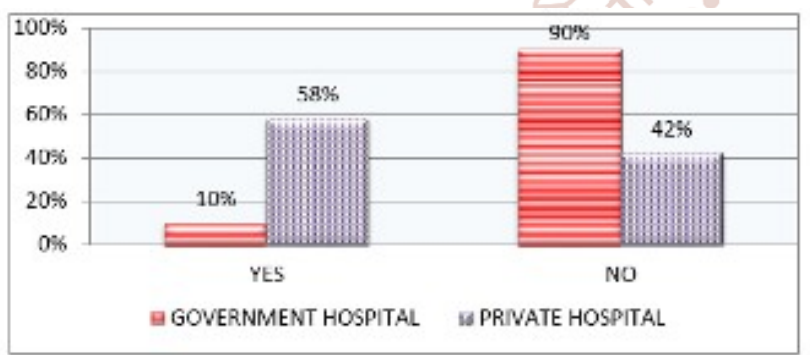

Figure-3: Received health care provider advice on physical activity during pregnancy

Table-2: Awareness regarding the recommended type of physical activity in pregnancy

\begin{tabular}{|c|c|c|c|c|}
\hline \multirow{2}{*}{ Type Of Hospital } & \multicolumn{2}{|c|}{ Awareness Regarding Type Of Physical Activity } & \multirow{2}{*}{ T-Value } & Result \\
\cline { 2 - 5 } & Correct & Incorrect & \multirow{2}{*}{0.006} & \multirow{2}{*}{ Insignificant } \\
\hline Government hospital & 9 & 41 & 23 & \\
\hline Private hospital & 17 & &
\end{tabular}

Knowledge of private and government hospital respondents, with respect to recommended type of physical activity, is insignificant with under $p$-value $<0.05$ with a $t$-value of 0.006 . This indicates that respondents from both the types of hospitals had no difference in knowledge with respect to the recommended type of physical activity in pregnancy.

Table-3: Practice of physical activity in pregnancy

\begin{tabular}{|c|c|c|c|c|}
\hline \multirow{2}{*}{ Type Of Hospital } & \multicolumn{2}{|c|}{ Practice Of Physical Activity } & \multirow[b]{2}{*}{ T-Value } & \multirow[b]{2}{*}{ Result } \\
\hline & Adequate & Inadequate & & \\
\hline Government Hospital & 33 & 17 & \multirow{2}{*}{6.00} & \multirow[b]{2}{*}{ Significant } \\
\hline Private Hospital & 13 & 37 & & \\
\hline
\end{tabular}

Practice of physical activity, being adequate or inadequate, among government and private hospital respondents, was found to be significant under $p$-value $<0.05$ with a $t$-value 6.00. This indicates that the respondents of government hospital performed physical activity more adequately when compared to private hospital respondent"s inspite of them being less aware of the recommended guidelines for physical activity during pregnancy. A study by Ribeiro and Milanez
(2011) on Knowledge, attitude and practice of women in Campinas, São Paulo, Brazil with respect to physical exercise in pregnancy, depicts that pregnant woman believe that physical activity is beneficial and were in favour of it, yet only $20 \%$ of them were found to be performing adequate physical activity during this period. These findings were in agreement with the current study with respect to respondents of private hospitals. 


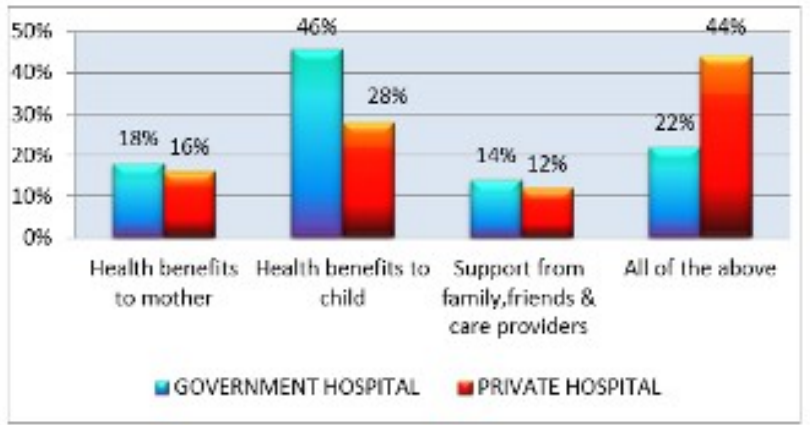

Figure-5: Promoters to physical activity in pregnancy

Figure- 5 indicates that health benefits to the child was identified as the main driving force for being physically active among the expectant mothers of government hospital, while a majority of expectant mothers of private hospital attributed not just one but all the listed promoters to be equally important drivers to physical activity in pregnancy.

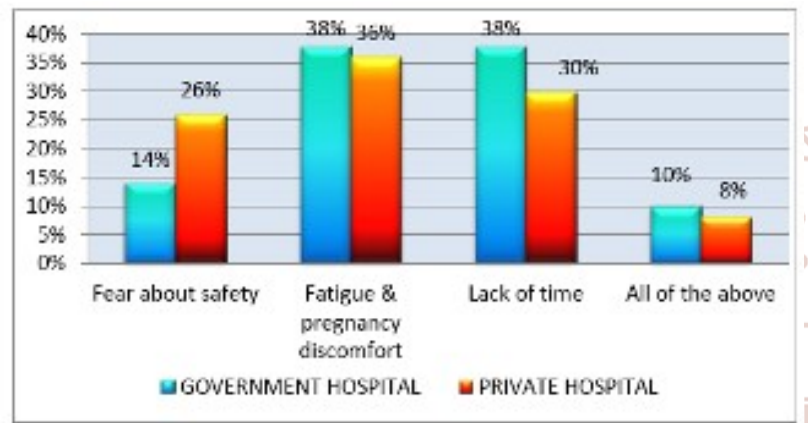

Figure-6: Barriers to physical activity in pregnancy

Figure- 6 depicts that fatigue and pregnancy discomfort, followed by lack of time was identified as the major barriers to the practice of physical activity in pregnancy. It is further evident that expectant mothers of private hospitals are avoiding exercise more frequently due to fear regarding the safety of exercising during pregnancy.

A study by Ribeiro and Milanez (2011) on Knowledge, attitude and practice of women in Campinas, São Paulo, Brazil with respect to physical exercise in pregnancy shows similar barriers being reported by pregnant women i.e., women reported tiredness, discomfort and lack of time as the factors responsible for avoiding physical activity in pregnancy.

\section{CONCLUSION}

The current highlights the need to inform the expectant mothers on the recommended type/ intensity of physical activity in pregnancy as majority of the women were reported lack of knowledge or incorrect knowledge about the recommendations of physical activity during pregnancy. Moreover, it was reported that the health care providers did not inform the pregnant women regarding physical activity in pregnancy, particularly in government hospital. But inspite of this deficit, it was observed that expectant mothers of government hospital performed more adequate physical activity than that of the private hospital women. This may be due to lack of sufficient income to hire a domestic help by the expectant mothers of the government hospital, unlike the expectant mothers of the private hospitals.
The study further elucidates that expectant mothers of government hospital majorly practiced physical activity due to health benefits it has on the child, but reported barriers to physical activity like fatigue and pregnancy discomfort, and lack of time. Contrarily, expectant mothers of private hospitals practiced physical activity because of overall health benefits to the mother as well as the child and also the support offered to them, but reported barriers like fatigue and pregnancy discomfort, and fear about the safety of physical activity.

\section{RECOMMENDATIONS}

$>$ This study can be extended to a larger sample to get more conclusive results.

$>$ The sample population could be given an education intervention and the response of it may be studied.

\section{ACKNOWLEDGEMENT}

The authors fully acknowledge Dr. LATHA SASHI, Consultant Nutritionist \& HOD, Department of Clinical Nutrition and Dietetics, Fernandez Hospital for providing her valuable ideas and inputs on this project

\section{BIBLIOGRAPHY}

[1] ACOG Committee Opinion No. 650: Physical Activity and Exercise during Pregnancy and the Postpartum Period. Obstetrics \& Gynaecology, 2015, 126(6), 135-142.

[2] Astrid Merkx, Marlein Ausems, Luc Budé, Raymond de Vries, Marianne J. Nieuwenhuijze. Factors affecting perceived change in physical activity in pregnancy. Midwifery, 2017, 51:16-23.

[3] Barakat R, Perales M, Bacchi M, Coteron J, Refoyo I. A program of exercise throughout pregnancy. Is it safe to mother and newborn? American Journal of Health Promotion, 2014, 29(1):2-8.

[4] Blaize A N, Pearson K J, Newcomer S C. Impact of maternal exercise during pregnancy on offspring chronic disease susceptibility. Exercise and Sport Sciences Review, 2015, 43:198-203.

[5] Carmen P.Ribeiro and Helaine Milanzer. Knowledge, attitude and practice of women in Campinas, São Paulo, Brazil with respect to physical exercise in pregnancy: a descriptive study. Reproductive health, 2011, 8, 31.

[6] Gaston A and Vamos CA. Leisure-time physical activity patterns and correlates among pregnant women in Ontario, Canada. Maternal and Child Health Journal, 2013, 17(3), 477-484.

[7] Hegaard H K, Pedersen B K, Nielsen B B, Damm P. Leisure time physical activity during pregnancy and impact on gestational diabetes mellitus, pre-eclampsia, preterm delivery and birth weight: a review. Acta Obstetricia et Gynecologica Scandinavica, 2007, 86:1290-1296.

[8] Perales M, Calabria I, Lopez C., Regular exercise throughout pregnancy is associated with a shorter first stage of labor, American Journal of Health Promotion, 2016, 30:149-154.

[9] Phelan S. Pregnancy: a "teachable moment" for weight control and obesity prevention. American Journal of Obstetrics and Gynecology, 2010, 202(2): 135 e131138. 
International Journal of Trend in Scientific Research and Development (IJTSRD) @ www.ijtsrd.com eISSN: 2456-6470

[10] Prather H, Spitznagle T, Hunt D. Benefits of Exercise during Pregnancy. PM \& R: the journal of injury, function, and rehabilitation, 2012, 4, 845-850.

[11] Tinloy J, Chuang C H, Zhu J. Exercise during pregnancy and risk of late preterm birth, cesarean delivery, and hospitalizations. Women"s Health Issues, 2014, 24: 99104.
[12] Data on Maternal and reproductive health, Available from: https://www.who.int/gho/maternal_health/en/.

[13] Physical activity, Available from: https://www.who.int/dietphysicalactivity/pa/en/.

[14] Recommendations on physical activity, Available from: https://www.acog.org/Patients/FAQs/ExerciseDuring-Pregnancy?

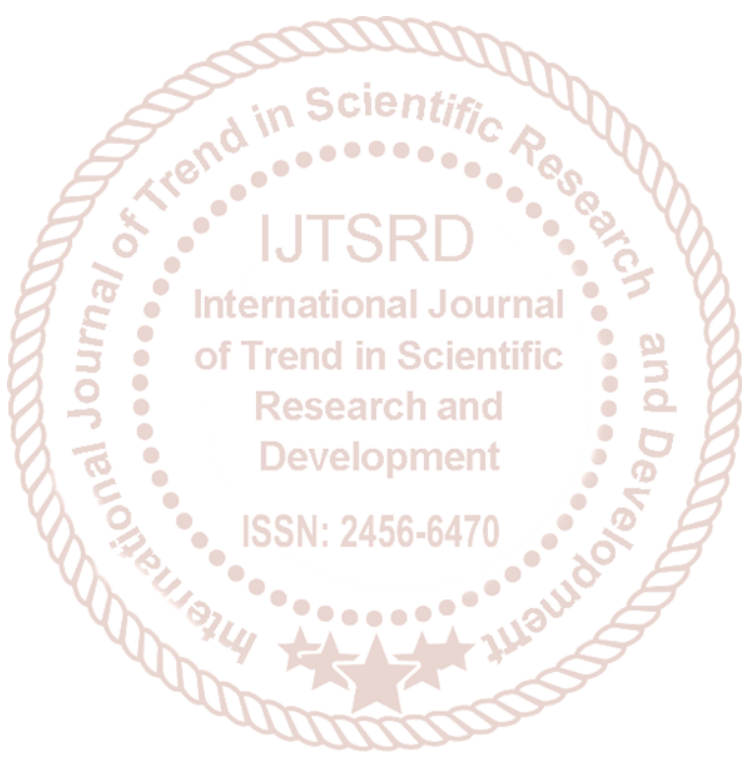

